\title{
Benefits and Success of an Interdisciplinary Wellness Interest Group (iWIG) at a Modern Jesuit University
}

\author{
Susan Bartos PhD, RN, CCRN \\ Mackenzie Gordon MS, RD, LDN \\ Catherine J. Andersen PhD, RD \\ Kara Hunter PhD, CPA \\ Fairfield University, Fairfield, Connecticut
}

\begin{abstract}
Aim: To highlight the early achievements and discuss the benefits of forming an Interdisciplinary Wellness Interest Group (iWIG) on a modern Jesuit University campus.

Background: While wellness programs have a place in academic communities, universal perspectives on the best way to lead Wellness initiatives is lacking. An iWIG gives a common platform to share ideas, communicate across audiences, and provide important information to the campus community about health promotion and health patterns of the campus community.

Methods: After assembling the iWIG team, on-campus meetings were held with members of the interdisciplinary group. These meetings include faculty, staff, and students from various departments. The iWIG continues to meet regularly to expand and develop wellness initiatives, research opportunities and to ensure a presence on campus.

Results: The iWIG has impacted many initiatives on campus, a select few which are profiled in this manuscript. The group is involved in funded research studies, has received a "Healthy Workplace" designation, and continues to expand health and wellness into various departments on campus.

Conclusions: The interdisciplinary group has provided those with an interest in health and wellness with a formal platform to express ideas and implement initiatives for all individuals to better the overall wellbeing of the university community.
\end{abstract}

Submitted 1 March 2018: accepted 25 September 2018

Keywords: Interdisciplinary, Collaboration, Wellness, University campus health

Staying well in a collegiate environment, where stressors are high for students, staff, and faculty, can pose a challenge (Deliens, 2015; Deshpande, 2009; Hill-Mey et al., 2015). At a Jesuit university, the value of caring for the whole person, or Cura Personalis, is embedded firmly throughout the curriculum, scholarly work, and campus initiatives (Streetman, 2015). At this university, an interdisciplinary Wellness Interest Group (iWIG) was formed to develop a cohesive and comprehensive program to support efforts that encompass the whole person: Body, mind, and spirit.

Originating in the School of Nursing and Health Studies, the iWIG includes faculty, staff, and students representing the College of Arts and Sciences, School of Business, Campus Health Center, Human Resources, Administration, Recreation, Food and Nutrition, and Academic/Administrative Deans. The group continues to recruit members as the opportunity for new wellness initiatives arises to further strengthen collaborative efforts on 
campus. Together, the development and success of the iWIG may serve as a template for implementing interdisciplinary wellness groups at other universities.

The early meetings of the iWIG were held to establish common interests, become acquainted with each other's roles on campus, and to establish common goals to achieve. In early meetings, it was discovered that the campus already had many ongoing and overlapping wellness initiatives. The iWIG served as a platform to share ideas, develop plans of action, and organize, communicate, or advertise these programs in an interdisciplinary setting. The inclusion of faculty, students, and staff allowed initiatives to be informed from pedagogical, scholarly, and administrative perspectives.

Through word of mouth communication and open invitations to meetings, the iWIG grew into a gathering of like-minded individuals dedicated to bringing a culture of health and wellness to all individuals on campus, in line with the American College Health Association Healthy Campus 2020 guidelines (American College Health Association, 2012). Meetings are open to new members, including students of both the undergraduate and graduate level. Representatives from the iWIG presented to University administration to spread awareness of the group and to provide updates regarding the progress towards health and wellness goals.

Health and wellness in the academic environment are priorities across many interest areas, encompassing nutrition, recreation, and mental health, including the management of stress in all individuals on campus. Representatives from each of these dimensions of wellness are invited to attend the iWIG meetings to share ideas for collaboration, promote programs, and maximize resources.

\section{FOOD AND NUTRITION}

Obesity is a rapidly growing public health priority and is altering the environment of students, staff, and faculty (Roy, Kelly, Rangan, \& Allman-Farinelli, 2015). A main priority of the campus RD is to promote a healthy food environment for those living and working in the academic setting. For the college-aged individual, the academic setting introduces a variety of unfamiliar environmental stressors. This may lead to increased weight gain due to high consumption of high fat or sugary foods, soft drinks, and reduction in foods with a high nutrient density on campus (Vella-Zarb \& Elgar, 2009; Christoph, Ellison, \& Meader, 2016). Additionally, between 5 and 10\% of students are consuming the daily recommended amount fruits and vegetables (Moore, Thompson, \& Demissie, 2017).

Through promotion and support of the iWIG, the University RD works to provide educational displays, cooking demonstrations, and creative approaches to cooking on a college budget to the campus population. The on-campus registered dietitian (RD) regularly attends the iWIG meetings to share nutrition information and updates from Dining Services with members of the interdisciplinary group. The RD oversees the choosing of the menus for on-campus dining and will often communicate information about special dietary concerns, holiday meals, and nutritional considerations to the iWIG. Menu items are prepared fresh with calorie and nutrient counts available at each station and are maintained by the campus dietitian.

Foods and beverages, which are lower in calories are more nutrient dense, are strategically placed around the campus dining hall. Altering the environment and placement of sugar sweetened beverages has been shown to be beneficial in reducing intake of sugar sweetened beverages and encourage students to consume water over sugar sweetened beverages (Montuclard et al., 2017; West et al., 2006). The stressors of college and unhealthy lifestyles can lead students to consume high-fat, and sugar diets that are low in fruits and vegetables and whole grains. Sugarsweetened beverages are contributing to the prevalence of obesity, diabetes, dental carries, and metabolic syndrome 
(Berkley, Rockett, Field, Gillman, \& Colditz, 2004; West et al., 2006). Sugar sweetened beverages represent a significant source of calories in the diet, which may lead to increased calorie consumption (Berkley et al., 2004).

The University RD was integral in the strategic planning of the location of the soda and juice dispensers throughout the dining hall. The dining hall developed a water hydration station separate from the soda and juice stations hoping to drive more students away from the sugar-sweetened beverages. The University RD provides educational materials to inform drink consumers of the amount of sugar content in popular sugared beverages and juices through the "Rethink Your Drink" campaign. It is the goal of the RD and of the iWIG to reduce sugarsweetened beverages on campus. The campus RD also oversees interactive and food positive programs such as "Fruit of the Week" and "Wellness Wednesday" which often feature a pedal-powered smoothie bike. This bike helps to thread together the importance of nutrition and physical health.

The personal health of the individual is supported by the RD through the availability of allergy-free kitchens and appropriate accommodations at the dining hall. Food allergies are on the rise, with approximately $7 \%$ of the national population reporting a food allergy (Marra et al., 2017). This growing concern influenced the design of the newly renovated dining hall to include allergy-friendly preparation and cooking stations. In this specialized space, diners with known food allergies can have their food prepared on surfaces that do not cross-contact with common food allergens. Two distinctive allergen-friendly areas in the hall are offered: one station is free of wheat, milk, eggs, peanuts, tree nuts, soy, and shellfish, and the second station, is free of gluten, tree nuts, and peanuts. These stations offer healthy and simple, yet flavorful foods to students with food allergies. This intervention allows for those affected with food allergies to dine safely and socially in an environment among the greater campus community.

Improving the physical health of all students, including the student athletes, is an early and emerging achievement of prioritizing health and wellness on campus through the iWIG. Athletes may improve their knowledge of nutrition through a campus RD (Beck, Thomson, Swift, \& Hurst, 2015). To provide athlete specific education, the university RD offers nutrition education sessions during preseason, individual counseling, or for sport-specific presentations. Coaches, athletes, and trainers are invited to attend.

The University is the first in the MACC tournament to implement a post-recovery fueling center. The fueling station offers student athletes a chance to refuel and improve energy levels and performance, specifically around workout times. As the relationship between the Nutrition and the athletic departments continues to mature, future goals include providing nutrition education individual sports, teaching students on how to properly fuel their bodies in the dining hall, and grocery supermarket tours. Representatives from recreation/athletics and nutrition attend and participate in the iWIG meetings, making it a convenient forum to exchange ideas and information.

With the establishment of the iWIG, as well as the recent significant institutional investments in Food and Nutrition and Recreational services outlined above, research initiatives have commenced to evaluate and promote current dietary and physical activity practices within the campus community. This is particularly important, as research studies have found that college students often fail to meet national recommendations and guidelines for dietary intake and physical activity, which may be associated with barriers related to transportation, affordability, time management, limited food choices, increased autonomy, and stress (Cousineau, Franko, Ciccazzo, Godstein, \& Rosenthal, 2006; Anding, Suminski, \& Boss, 2001; Deliens, 2015). Optimizing healthy nutrition and physical activity practices can improve memory and concentration, mental health, stress responses, weight management, and can contribute to establishing healthy lifestyle patterns through adulthood (Norris, Caroll, \& Cochran, 1992; Elias, Elias, Sullivan, Wolf, \& D’Agostino, 2003; Cousineau, 2006). 
With funding support from a National Consortium for Building Healthy Academic Communities (NCBHAC) Evidence-Based Practice Grant, Biology Department faculty and students have embarked on campus assessment activities, in collaboration with iWIG members, the campus dietitian, and the Recreation center staff. Campus health interventions have been found to be most effective when they (1) were tailored to individual students within specific populations (e.g., first-year students), (2) incorporated peer education, (3) created opportunities for interactions with professionals in specialized fields of health, (4) provided online, readily-accessible resources to continuing education, and (5) and provided tools for personalized feedback and monitoring (Cousineau et al., 2006; Kelly, Mazzeo, \& Bean, 2013; Poddar, Hosig, Anderson, Nickols-Richardson, \& Duncan, 2010; Deshpande, Basil, \& Basil, 2009), which were used to set parameters for assessment. Discussions within the iWIG meetings further helped to shape and inform the development of grant proposal goals and objectives, thereby allowing the project to achieve a broader scope than if it had been devised independently.

Ongoing activities related to this grant-funded work include evaluating the nutritional quality of food offerings across campus (e.g., the dining hall, vending machines, external vendors, grab-and-go meal stations) and Recreation center usage. In addition, the student population is being surveyed to identify patterns and barriers with using campus health resources, as well as identify associations between academic status and health practices. Undergraduate research student involvement in this project has led to dissemination of wellness objectives at the university and national level via numerous capstone projects, participation in on-campus research symposiums, and peer-review presentations at the American Society for Nutrition annual conference in June 2018 (Cintron-Rivera, Dupree, Gaito, Murray, \& Anderson, 2018; Dupree, Cintron-Rivera, Gaito, \& Andersen, 2018; Gaito, Cintron-Rivera, Dupree, \& Andersen, 2018). Ultimately, findings from this study will not only contribute to the greater body of knowledge regarding University student lifestyle practices, but will directly inform campus initiatives aimed at optimizing access to health resources.

\section{PHYSICAL MOVEMENT AND RECREATION}

Physical activity is an important lifestyle factor that contributes to overall health and a reduced risk of chronic disease. Among students, participation in physical activity has been shown to decrease in the transition to college, in addition to years throughout college (Deliens, Deforche, Bourdeaudhuij, \& Clarys, 2015). Membership in health clubs has been associated with increased physical activity, as well as more favorable lifestyle practices and cardiovascular health markers (Schroeder, Welk, Franke, \& Lee, 2017; Ready, Naimark, Tate, \& Boreskie, 2005), University campus-based worksite wellness programs have additionally been shown to be effective at improving physical activity practice and health outcomes in university employees (Butler, Clark, Burlis, Castillo, \& Racette, 2015).

The iWIG has representation from the Recreation Complex (RecPlex) and works to promote activity on campus through movement. One of the first successful initiatives of the iWIG was to reduce the yearly membership rate of the RecPlex from $\$ 150$ to $\$ 50$ a year for faculty members through advocacy of WIG members to University administrators. Currently, nearly $20 \%$ of members of the faculty and staff use the RecPlex facilities. This yearly membership includes full access to all areas of the facility. The brand new recreation complex also features, an upperlevel mezzanine for cardio equipment; strength training \& cardio suites, basketball, tennis, volleyball courts, indoor track, renovated locker rooms and group fitness areas, including a cycling studio. A biometrics screening device has been added to the recreation center giving students, faculty, and staff the ability to monitor more advanced measures 
of fitness progress such as lean body mass, skeletal muscle mass, water distribution, and body composition. Users are provided proper privacy when using the machine and are educated on its appropriate and responsible use.

The director of recreation works closely with members of the iWIG to promote events how physical health affects the other dimensions of wellness. Special events are featured in the recreation complex during exam weeks and health specific education is often conducted in the lobby of the RexPlex. The iWIG e-mail distribution list is used to distribute promotional offers to the RecPlex. Conversations focused around supporting these initiatives are often started, continued, and grow within the iWIG.

\section{STRESS MANAGEMENT AND MENTAL HEALTH}

In the high-stress and high-anxiety climate of the collegiate environment, students are often left without a place to "unplug." The University recently renovated and added a 70,000 square foot, four-level structure to the existing nursing school. This expansion and additional space allowed for new opportunities to blend high-tech and modern academics with areas of rest and wellbeing. In the School of Nursing and Health Studies, there is a designated "Wellness Room." In this room, users are encouraged to leave all electronic devices and study outside of the room. The room is decorated with soothing images, soft lighting, relaxing music, and comfortable seating. The iWIG has recently begun working with art students on campus to create custom artwork for the Wellness Room. This partnership has dual benefit, as it fulfills the creativity facet of wellness for the art students and provides a therapeutic and soothing milieu for those wanting to find a serene environment on campus.

For the individual that may prefer pet therapy, a licensed therapy dog, Dakota, is often available for companionship. Interacting with dogs may help to alleviate stress and improve the mood of college students (Delgado, Toukonen, \& Wheeler, 2018). Dakota is available to help with feelings of loneliness, anxiety, or for those wanting some exercise, or those who need a companion, she is available for a walk around campus. Dakota has made appearances during high stress times, such as exams, and students report feeling calmer and in better control of stress and testing anxiety. Using pet therapy to help students reduce test anxiety has demonstrated positive student outcomes (Young, 2012). Anecdotally, students, faculty, and staff who interact with Dakota are often pleased by her company and her appearance during campus events helps to draw a crowd. Dakota is also an enthusiastic member of the Wellness Interest Group, attends the monthly meetings, and has attended many of the Wellness events.

\section{DISCUSSION}

Forming a successful wellness and health promotion group on campus requires strong leadership support, health education, environmental and cultural supports, champions of wellness efforts, and aligning behaviors and outcomes with measurable benefits to the greater community (Amaya, Melnyk, Buffington, \& Battista, 2017). Like many wellness programs, this iWIG stemmed from a "grass roots" effort. It began as a gathering of like-minded individuals who were champions of optimal health behaviors and grew into a collective campus voice. Sustainability for the next generation of the workforce is imperative to the stability and advancement of multiple industries and career paths. Instilling and promoting healthy behaviors during the influential time of a college student's development aids in creating positive, engaged individuals who are future-minded (Visser \& Hirsch, 2014).

Nursing organizations such as the American Association of Critical Care Nurses (AACN) advocate for a healthy work environment and call for a multifaceted and holistic approach to the work environment (AACN, 2016). These 
six standards serve as a framework for implementing a healthy work environment in clinical practice; however, because the academic setting is also a workplace environment for many clinicians, a seventh standard has been purposed (Harmon, DeGennaro, Norling, Kennedy, \& Fontaine, 2018). This seventh academic standard calls for faculty and staff to engage in and, "are supported in developing self-care as foundational to the creation of a healthy work and learning environment where all members of the academic community can thrive” (Harmon et al., 2018, p. 22).

\section{CHALLENGES AND LIMITATIONS}

There have been challenges with implementing this interdisciplinary group. As the iWIG continues to grow, finding a common meeting time to accommodate the schedules of its members has been an issue. This has been contented by providing prompt meeting minutes and summaries, or providing a virtual meeting-ID. Changes in members and in University administration also present a challenge. Certain initiatives, which require diligent follow-through, are difficult to track due to student leaders graduating or changes in University staff. As health and wellness grows as a priority on campus, the University is looking to incorporate innovate solutions to ensure the sustainability of campus wellness efforts.

\section{CONCLUSION}

The iWIG continues to grow and expand into more disciplines. It is our hope to weave health and wellness throughout undergraduate and graduate education, and into both faculty and staff career development. Dissemination of the development of the program is important to the vitality of the iWIG so colleagues and peers may benefit at collegiate institutions nationwide. 


\section{REFERENCES}

Amaya, M., Melnyk, B.M., Buffington, B., \& Battista, L. (2017). Workplace Wellness Champions: Lessons learned and implications for future programming. Building Healthy Academics Communities Journal, 1(1), 59 - 67. https://doi.org/10.18061/bhac.v1i1.5744

American Association of Critical Care Nurses (2016). AACN standards for establishing and sustaining healthy work environments: Executive summary, $2^{\text {nd }}$ edition. Retrieved from: https://www.aacn.org/ /media/aacnwebsite/nursing-excellence/healthy-work-environment/execsum.pdf?la=en

American College Health Association. (2012, June). Healthy Campus 2020. Retrieved August 21, 2018, from https://www.acha.org/HealthyCampus/HealthyCampus/Map-It_Framework.aspx\#mobilize.

Anding, J.D., Suminski, R.R., Boss, L. (2001) Dietary intake, body mass index, exercise, and alcohol: Are college women following the dietary guidelines for Americans? Journal of American College Health, 49; 167-171. https://doi.org/10.1080/07448480109596299

Berkley, C.S., Rockett, H., Field, A.E., Gillman, M.W., \& Colditz, G. (2004). Sugar-added beverages and adolescent weight change. Obesity Research, 12, 778-88. https://doi.org/10.1038/oby.2004.94

Butler, C.E., Clark, B.R., Burlis, T.L., Castillo, J., \& Racette, S.B. (2015). Physical activity for campus employees: A university worksite wellness programs. Journal of Physical Activity and Health, 12(4), 470-476. https://doi.org/10.1123/jpah.2013-0185

Beck, K.L., Thomson, J.S., Swift, R.J., \& Hurst, P.R. (2015). Role of nutrition in performance enhancement and post exercise recovery. Open Access Journal of Sports Medicine, 6, 259-267. https://doi.org/10.2147/OAJSM.S33605

Christoph, M.J., Ellison, B.D., Meador, E.N. (2016). The influence of nutrition label placement on awareness and use among college students in a dining hall setting. Journal of the Academy of Nutrition and Dietetics, 116(9), 1395-1405. https://doi.org/10.1016/j.jand.2016.05.003

Cintron-Rivera, L., Dupree, L., Gaito, A., Murray, K., \& Andersen, C.J. (2018). Nutritional quality of university dining options varies by location and level of convenience. Current Developments in Nutrition, In Press.

Cousineau, T.M., Franko, D.L., Ciccazzo, M., Goldstein, M., \& Rosenthal, E. (2006). Web-based nutrition education for college students: Is it feasible?, Evaluation Program and Planning, 29, 23-33. https://doi.org/10.1016/j.evalprogplan.2005.04.018

Delgado, C., Toukonen, M., \& Wheeler, C. (2018). Effect of canine play interventions as a stress reduction strategy in college students. Nurse Educator, 43(3), 149-153.

Deliens, T., Deforche, B., De Bourdeaudhuij, I., Clarys, P. (2015). Determinants of physical activity and sedentary behaviour in university students: a qualitative study using focus group discussions. BMC Public Health, 15, 201. https://doi.org/10.1186/s12889-015-1553-4

Deshpande, S., Basil, M.D., \& Basil, D.Z. (2009). Factors influencing healthy eating habits among college students: an application of the health belief model. Health Marketing Quarterly, 26, 145-164. https://doi.org/10.1080/07359680802619834 
Dupree, L., Cintron-Rivera, L., Gaito, A., \& Andersen, C.J. (2018). Nutrient composition of food offerings varies across themed university campus meal stations. Current Developments in Nutrition, In Press.

Elias, M.F., Elias, P.K., Sullivan, L.M., Wolf, P.A., \& D'Agostino, R.B. (2003). Lower cognitive function in the presence of obesity and hypertension: the Framingham heart study, International Journal of Obesity Related Metabolic Disorders, 27, 260-268. https://doi.org/10.1038/sj.ijo.802225

Gaito, A., Cintron-Rivera, L., Dupree, L., \& Andersen, C.J. (2018). Evaluating the nutritional quality of university dining hall foods across meals and calendar days. Current Developments in Nutrition, In Press.

Harmon, R.B., DeGennaro, G., Norling, M., Kennedy, C., \& Fontaine, D. (2018). Implementing healthy work environment standards in an academic workplace: An update. Journal of Professional Nursing, 34(2018), 20-24. https://doi.org/10.1016/j.profnurs.2017.06.001

Hill-Mey, P.E., Kumpfer, K.l., Merrill R.M., Reel, J., Hyatt-Neville, B., \& Richardson, G.E. (2015). Worksite health promotion programs in college settings. Journal of Education and Health Promotion, 4, 12. https://doi.org/10.4103/2277-9531.154019

Kelly, N.R., Mazzeo, S.E., \& Bean, M.K. (2013) Systematic review of dietary interventions with college students: Directions for future research and practice, Journal of Nutrition Education and Behavior, 45, 304-313. https://doi.org/10.1016/j.jneb.2012.10.012

Kerksick, C., Harvey, T., Stout, J., Campbell, B., Wilborn, C., Kreider, R., ... \& Ivy, J. L. (2008). International Society of Sports Nutrition position stand: nutrient timing. Journal of the International Society of Sports Nutrition, 5(1), 17. https://doi.org/10.1186/1550-2783-5-17

Marra, C. A., Harvard, S., Grubisic, M., Galo, J., Clarke, A., Elliott, S., \& Lynd, L. D. (2017). Consumer preferences for food allergen labeling. Allergy, Asthma \& Clinical Immunology, 13(1), 19. https://doi.org/10.1186/s13223017-0189-6

Montuclard, A.L., Mroch, J.P., O’shea, A.M.J., Brian, W., Irvin, J., \& Laroche, H.H. College cafeteria signage increases water intake but water position on the soda dispenser encourages more soda consumption. Journal of Nutrition Education and Behavior,49, 764-771. https://doi.org/10.1016/j.jneb.2017.05.361

Moore, L.V., Thompson, F.E., Demissie, Z. (2017). Percentage of youth meeting federal fruit and vegetable intake recommendations, Youth Risk Behavior Surveillance System, United States and 33 states, 2013. Journal of the Academy of Nutrition and Dietetics, 117(4), 545-553. https://doi.org/10.1016/j.jand.2016.10.012

Norris, R., Carroll, D., \& Cochrane, R. (1992) The effects of physical activity and exercise training on psychological stress and well-being in an adolescent population. Journal of Psychosomatic Research, 36, 55-65. https://doi.org/10.1016/0022-3999(92)90114-H

Poddar, K.H., Hosig, K.W., Anderson, E.S., Nickols-Richardson, S.M., \& Duncan, S.E. (2010). Web-based nutrition education intervention improves self-efficacy and self-regulation related to increased dairy intake in college students. Journal of the Academy of Nutrition and Dietetics, 110, 1723-1727. https://doi.org/10.1016/j.jada.2010.08.008

Ready, A.E., \& Naimark, B.J., \& Tate, R., \& Boreskie, S. (2005). Fitness centre membership is related to healthy behaviours. The Journal of Sports Medicine and Physical Fitness, 45, 199-207. 
Roy, R., Kelly, B., Rangan, A., \& Allman-Farinellu, M. (2015). Food environment interventions to improve the dietary behavior of young adults in tertiary education settings. A systematic literature review. Journal of the Academy of Nutrition and Dietetics, 115, 1647-1681. https://doi.org/10.1016/j.jand.2015.06.380

Schroeder, E.C., Welk, G.J., Franke, W.D., \& Lee, D. (2017). Associations of health club membership with physical activity and cardiovascular health. PLoS One, 12(1): e0170471. https://doi.org/10.1371/journal.pone.0170471

Streetman, H. (2015). Jesuit values, Ignatian pedagogy, and service learning: Catalysts for transcendence and transformation via action research. Jesuit Higher Education: A Journal, 4, 36-50.

Vella-Zarb, R.A., \& Elgar, F.J. The 'Freshman 5': A meta-analysis of weight gain in the freshman year of college. Journal of American College Health, 58(2), 161-166. https:/ / doi.org/10.1080/07448480903221392

Visser, P. L., \& Hirsch, J.K. (2016). Health behaviors among college students: The influence of future time perspective and basic psychological need satisfaction. Health Psychology and Behavioral Medicine, 2(1), 88-99. https://doi.org/10.1080/21642850.2013.872992

West, D. S., Bursac, Z., Quimby, D., Prewitt, T. E., Spatz, T., Nash, C., ... \& Eddings, K. (2006). Self-reported sugar-sweetened beverage intake among college students. Obesity, 14(10), 1825-1831. https://doi.org/10.1038/oby.2006.210

Young, J. S. (2012). Pet therapy: Dogs de-stress students. Journal of Christian Nursing, 29(4), 217-221. https://doi.org/10.1097/CNJ.0b013e31826701a7

Address Author Correspondence to:

Susan Bartos PhD, RN, CCRN

Marion Peckham Egan School of Nursing and Health Studies

1073 North Benson Road

Fairfield, CT 06824

sbartos@fairfield.edu

\section{Author notes/acknowledgements}

The authors of this manuscript acknowledge all members of the interdisciplinary wellness group and their inspiring contributions to forge a culture of health and wellbeing on this campus. 